\title{
Analysis on the Causes for the Loss of the International Joint Hotel and Its Countermeasures
}

\author{
Meng Xu \\ Hospitality Management Specialty, School of Tourism Management, Tianjin Vocational Institute, Tianjing, \\ 300410
}

Keywords: International Joint Hotel, Guest Loss and Countermeasures, Service Level

\begin{abstract}
As an increasingly competitive hotel industry, only by attaching importance to human capital, formulating a reasonable human resource management system, and rationally planning human resources can retain employees and improve their competitiveness. By analyzing the current situation and characteristics of the hotel, this paper puts forward some countermeasures and suggestions for hotel development.
\end{abstract}

\section{Introduction}

In today's society, the development of enterprises is increasingly dependent on high-quality professionals. The demand for human resources in the service industry is self-evident. However, in recent years, the crisis of employment shortage has not subsided, and the hotel industry has been seriously affected. On the one hand, the hotel human resources department can not recruit suitable employees; on the other hand, the turnover rate of hotel staff is high, and some even seriously affect the normal operation of the hotel. Especially in the first-line departments of hotels, such as the food and beverage department, the guest room department, etc., during the peak season of the hotel, due to the shortage of staff, a large number of temporary workers were employed to maintain normal operations, but the practice of making up the number like this can only be suspended. It does not solve the essential problem. Because a large number of temporary workers are not subject to formal training, they are not familiar with business skills and cannot give customers a good service experience. Furthermore, the hotel must cultivate its own capable workforce, which is more beneficial to the long-term development of the hotel. Therefore, in this situation, how to effectively leave employees and reduce the turnover rate of employees is crucial to the development of the hotel.

\section{Hotel staff turnover status}

With the development of China's economy and the strategic adjustment of the economic structure, tourism, as one of the sunrise industries of China's national economy, has become increasingly prominent in the national economy. As an important part of the tertiary industry, the hotel industry is becoming increasingly competitive. The competition among hotels is increasingly reflected in the competition between talents and the overall quality of employees. This competition is actually a contest of human capital of hotels. 1 The high turnover rate of modern hotel industry staff has become a problem that plagues hotel managers. The high turnover rate of hotels is not only found in China, it is an international issue. In the era of economic globalization, there is also a phenomenon of staff loss in hotels in developed countries. Relevant data show that the turnover rate of general enterprises is between $5 \%$ and $10 \%$, and the most suitable turnover rate for tourism hotels should be About $8 \%$, the annual turnover rate of hotel talents in developed countries is $15 \%$ to $20 \%$. However, according to a survey conducted by the China Tourism Association on star-rated hotels in China, the turnover rate of tourist hotels in China is as high as $23.95 \%$. It can be seen that the turnover rate of hotel staff in China is far higher than the international level. 


\section{Negative impact of hotel staff turnover}

According to the survey statistics, the hotel maintains an employee turnover rate of around 8\%, which is very beneficial for hotel development. Such employee turnover rate can stimulate the vitality of the company, mobilize the enthusiasm of employees, and benefit the realization of organizational goals. However, the high turnover rate will bring a heavy financial burden to the hotel. For example, the cost of recruiting employees, the need for training for employees to call in will also result in no lower costs. 3 If the loss is a very capable employee, then the loss of the hotel cannot even be measured by money. Therefore, the loss of employees is huge for hotels. How to retain talents and allocate human resources should be the top priority.

The loss of hotel staff will also seriously affect the quality of hotel services. On the one hand, because the employees and new employees are bound to have great differences in business skills, the growth of new employees requires training and needs to be exercised. These take time. In this alternating period, new employees will lack all aspects of their experience and skills. Seriously affect the quality of service and affect the service experience for guests. 4 On the other hand, during the period when the old employees are about to leave, due to the mentality, the quality of their services will be greatly reduced.

The loss of employees will affect the team atmosphere of the entire hotel, because the emotions of employees will affect each other. When an employee leaves the company, it may not affect much, but when a group of employees leave, they will send a signal to other employees. This kind of signal implies that there is a better chance outside or there is a problem with the operation of the hotel. The release of this signal is very unfavorable for the development of the hotel, and the enthusiasm of the staff in the post will inevitably be affected. Will start actively looking for new directions.

\section{Characteristics of hotel staff turnover}

Through the analysis of the current situation of hotel staff turnover, the employee turnover problem mainly presents the following characteristics: First, employee turnover is seasonal, and employee turnover is more serious in spring and winter. Most employees leave during the winter and spring transition period, that is, after the Spring Festival. When leaving the company, he will leave directly. The end of the student's internship period is also a period of serious employee turnover. A large number of students will not return after returning to school. Second, the age of lost employees tends to be younger. The majority of employees are 18 to 35 years old. The number of employees who are between 18 and 25 years old is relatively large. The number of employees who are over 45 years old is only very small. In part, the overall phenomenon of young employees leaving the company is serious. Third, the working hours of the lost employees tend to be short-term: the maximum proportion of employees leaving the work after one year of work is the largest proportion of the total number of employees leaving the job, and the second is the share of the total number of employees who leave the job for less than 6 months. Worked for more than 2 years. In short, the shorter the working hours in the hotel, the easier it is to leave. On the contrary, the longer the working time, the less likely it is to leave. Fourth, the reasons for employee turnover are diversified: Nearly half of the employees who leave the company are due to dissatisfaction with the hotel's internal system, such as: dissatisfaction with the hotel's salary and welfare system, training promotion system, etc. It is because of personal reasons, such as: marriage, family opposition to work, etc.; some employees did not return after the Spring Festival, other intern students naturally left the job at the end of the internship period; and some employees are dissatisfied with the disharmony between employees, and other parts Employees are full of concerns about the hotel's development prospects. Therefore, various reasons have led to employee turnover. 


\section{Suggestions and Countermeasures for Hotel Staff Loss}

The hotel is currently in the development stage, the operating income is seriously affected by the season, and the income of employees is also greatly affected. Some hotels and travel agencies seek long-term cooperation to retain more customers with multi-level, multi-level dining accommodation. At the same time, employees and managers are encouraged to use their personal connections to add business or a single order to the hotel, and to reward the winner with the corresponding amount according to the size of the single amount. In the off-season of tourism, we should actively seek ways to jointly organize preferential activities with a number of travel agencies to attract tourists and avoid the serious differentiation of tourists during the peak season and off-season. This will ensure the passenger flow, ensure the hotel's turnover, improve the hotel's own competitiveness, but also protect the income of employees, to avoid the phenomenon of employees leaving their jobs because they can not earn money in the off-season.

First, strengthen training. New employees are trained in various ways such as projectors, lectures, and scenario simulations, and the progress or results received by employees after training are included in the assessment. When employees are on the job, the training organized by the hotel should highlight its future development direction, as well as the plans for development in the next few years and the ultimate goal to be achieved, so that employees can plan their careers while understanding the direction of the hotel. After working for a period of time, department managers should often find their conversations to understand the work situation, and invite the human resources department to make suggestions or opinions for the employee's personal career planning, to make their career planning and hotel development vision consistent, and to achieve democracy. Management, let employees become managers of hotels, participate in management, and achieve the common growth and development of employees and hotels.

Second, adjust the salary structure. First, investigate the salary of star-rated hotels, understand the market salary level, adjust the salary level accordingly, adjust the salary to the market average, or slightly higher than the market salary average. In the case of employees who are working at work, the need to deduct money becomes an invisible deduction, that is, a certain amount of wages becomes an assessment salary, when there is no mistake in the employee's work. You can take the final salary plus the assessment salary. If the employee has a work mistake, the corresponding amount is deducted from the assessment salary. The same is the deduction of money, which is not easy to cause dissatisfaction of employees, but also promotes employees to work seriously.

Third, improve the promotion system. In response to the development of the hotel industry, we will develop a promotion system that is in line with the hotel's own development and is in line with the promotion needs of employees. The company should set the work content, job requirements, job responsibilities for each position, and let the company staff clearly define the requirements of each position. At the same time, internal staff rotation is implemented, so that employees are familiar with the work content of each position and are familiar with the business, which is helpful for employees to find jobs that are of interest and suitable for them. The promotion of employees adopts a model of fair competition. The internal competition of the company should clearly define the competitive recruitment process and be conducted in a fair, just and open manner, giving employees a platform and opportunity for development promotion.

Fourth, material incentives and spiritual incentives are combined. For employees who perform well at work, they must not only be given material rewards, including bonuses, necessities, or hotel vouchers, which can be given to friends and relatives or used by themselves. There must also be spiritual rewards. When employees meet the requirements of the company for outstanding employees, they will be nominated and praised at the staff meeting, given a certain amount of paid vacation, organized to travel and other methods to promote employees' hard work, and at the same time Special incentives attract employees.

Create a good working atmosphere. A good working and living environment is also an incentive for employees. A good interpersonal atmosphere is an important prerequisite for making employees happy and efficient. It makes the hotel full of vitality and vitality, so that the team maintains high 
morale and enables employees to experience the good work. Effective interpersonal atmosphere management not only promotes mutual trust among employees, but also helps to cultivate the team spirit of employees, so that employees feel comfortable and enjoy teamwork. 10 to ensure that employees can communicate freely and equally in the hotel, to maximize the enthusiasm and creativity of employees. Managers should care for their employees from the heart, make full use of various channels to contact employees, and communicate with employees in an informal manner to win the trust and loyalty of employees. Managers should fully respect and trust their employees and let employees feel The warmth of home brings employees to a sense of belonging to the hotel and regards the hotel as a matter of their own. This emotional maintenance is a powerful internal driving force. This kind of power can greatly mobilize the enthusiasm of employees and enhance the sense of responsibility of employees. Resounding a strong vitality.

\section{Conclusion}

At present, the hotel is in the development stage, and the problem of employee turnover is more serious. Only by reducing employee turnover rate and retaining effective employees can we improve market competitiveness. Therefore, this paper analyzes the external environment of hotel industry development and the conditions of the hotel itself, and proposes corresponding countermeasures. Through the combination of theory and practice, it can solve the problem of serious staff turnover, reduce the turnover rate and improve employee satisfaction. Degree and loyalty are important for companies to retain talent and improve international competitiveness.

\section{References}

[1] Wang Fubo. A comprehensive review of the research on the theory of human resources in and outside the country [J]. Modernization of shopping malls, 2008, 1 (late issue).

[2] Li Dexun. Research on employee turnover in star hotels [D]. Corporate Strategy, 2013, 1(1).

[3] Cheng Hao. Management countermeasures for hotel employee turnover problems [D]. 2012.

[4] Wang Siping. Exploring the causes and countermeasures of hotel staff turnover in China [D]. 2009.

[5] Cui Miaomiao. Analysis of the problem of staff turnover in tourist hotels and countermeasures [J]. Business strategy, 2015. 